Diabetologia 11, 57-62 (1975)

(C) by Springer-Verlag 1975

\title{
Glucose, Glucose-6-Phosphate, Lactate and Pyruvate Content of the Retina, Blood and Liver of Streptozotocin-Diabetic Rats Fed Sucrose- or Starch-Rich Diets
}

\author{
H. Heath, S. S. Kang and D. Philippou \\ Department of Biochemical Pathology, University College Hospital Medical School, London, England \\ Received: May 20, 1974, and in revised form: October 22, 1974
}

\begin{abstract}
Summary. The feeding of starch- or sucrose-rich diets to normal rats for 20 days resulted in a significant increase in lactate level and $\mathrm{L} / \mathrm{P}$ ratio in the retina in the sucrose-fed animals. There was no correlation between the glucose and lactate content of the blood and retina and it was concluded that the increased lactate content of the retina was derived from the fructose moiety of the sucrose. Liver hypertrophy occurred in both normal and diabetic animals fed the sucrose diet. When streptozotocin-diabetic rats were maintained for 20 days on the same diets significant increases in the lactic
\end{abstract}

acid content of the blood and liver occurred, but the high level of lactate in the retina of the sucrose-fed normal rats was not further elevated. The feeding of sucrose to diabetic rats resulted in better metabolic control of both blood glucose and lactate as compared with the maintenance of these animals on a starch diet.

Key words: Streptozotocin-diabetes, retina, liver hypertrophy, sucrose diet, lactate-pyruvate ratio, glucose-6-phosphate, glucose.
The maintenance of a local strain of rats for 8 to 12 months on a diet in which the sole carbohydrate source was sucrose has been reported [1] to result in impaired glucose tolerance, albuminuria with diffuse capillary glomerosclerosis and a retinopathy similar in many respects to that found in spontaneously diabetic animals and in nonproliferative stages of diabetic retinopathy in man. Alterations in the electroretinogram in rats which had been fed a sucrose-rich diet for 90 days have previously been demonstrated [2] and these were attributed to a disturbance in the metabolism of the retina, possibly due to a variation in capillary permeability. In 1968 an increase in soluble collagen content and a change in the ratio of insoluble to soluble collagen was shown to occur in the aorta of rats fed a high-sucrose diet, compared with animals fed a high-starch diet [3]. Thickening of the vascular basement membrane is well established in human diabetic microangiopathy and an increase in the hydroxyproline content of the human diabetic retinal vascular system, reflecting the increase in this hydroxyproline rich tissue, has been observed [4]. Focal thickening of the capillary basement membrane has been demonstrated $[5,6]$ to occur in the retinas of streptozotocin-diabetic rats maintained on a stock diet for 6 to 12 months and these animals also develop many of the pathological changes characteristic of a mild human diabetic retinopathy. The formation of numerous microaneurysms and neovascularisation did not occur.

Investigations into the cause of human diabetic retinopathy have been hindered by the absence of a suitable animal model. In an attempt to produce a diabetic animal which readily develops all the pathological changes which normally occur in human retinopathy, it was decided to maintain streptozotocindiabetic rats for up to 12 months on a diet in which the sole source of carbohydrate was sucrose and subsequently to examine histologically the retinal vascular system in order to determine whether the feeding of sucrose to the diabetic animal either accelerated or exacerbated the retinopathy. These results will be reported at a later date, but during the course of this experiment another series of normal and streptozotocin-diabetic rats were fed either a starch- or sucroserich diet for 20 days before sacrifice and analysis of the retina, blood and liver. High levels of lactic acid in the retina have been implicated in the development of diabetic retinopathy [7], but no actual values have so far been reported in the literature for the lactic acid content of the retinas from diabetic animals. An increase in the lactic acid content of the retinas from normal and alloxanised rats in which the blood glucose level was varied by the parenteral administration of either glucose or insulin has been observed [7] and it is not, therefore, unreasonable to expect that lactic acid will increase in the retinas during diabetic hyperglycaemia. The administration of sucrose to normal humans has been shown to induce a greater increase in the blood lactic acid content than the comparable administration of dextrose [8]. It was decided, therefore, to determine the glucose, glucose-6-phosphate, 
lactic acid and pyruvic acid content of the retina, liver and blood of normal and diabetic rats fed either a starch- or sucrose-rich diet for 20 days, so as to ascertain, firstly, whether these regimens markedly affected the redox state of the tissues and, secondly, to see what effect a high intake of sucrose had on the glucose content of the tissues and the extent to which phosphorylation occurred.

\section{Materials and Methods}

\section{Animals}

32 male Wistar rats $(180-200 \mathrm{~g})$ were fed ad libitum on synthetic diets (the compositions of which are shown below) containing either sucrose or starch as the sole source of carbohydrate. The rats were divided into 4 groups. Those from 2 groups were rendered diabetic by the injection of $50 \mathrm{mg}$ streptozotocin $/ \mathrm{kg}$ body weight into the tail vein. The presence of diabetes was established by polyuria, glycosuria, failure to gain weight and terminal blood glucose. 1 normal and 1 diabetic group were maintained on each diet for 20 days before sacrifice.

\section{Diets}

The composition of the diets was, in parts by weight: carbohydrate (corn starch or pulverised sucrose) 68; Casumen (sodium caseinate) 23; salt mixture 4 ; vitamin mixture 2 ; cellulose as solka floc 3 ; corn oil 0.9 . The salt mixture had the following composition: $(\mathrm{g} / \mathrm{kg}) \mathrm{CaHPO}_{4} 325 ; \mathrm{CaCO}_{3} 205 ; \mathrm{KCl}$ 205; $\mathrm{Na}_{2} \mathrm{HPO}_{4}$ 185; $\mathrm{MgSO}_{4} \cdot \mathrm{H}_{2} \mathrm{O} 70 ; \mathrm{MnSO}_{4} \cdot \mathrm{H}_{2} \mathrm{O}$ 4.5; ferric citrate $5 \mathrm{H}_{2} \mathrm{O} 4.4 ; \mathrm{ZnCO}_{3} 0.75 ; \mathrm{CuSO}_{4}$. $5 \mathrm{H}_{2} \mathrm{O} 0.38 ; \mathrm{KIO}_{3} 0.025$.

The vitamin mixture had the following composition: $(\mathrm{g} / \mathrm{kg})$ ascorbic acid 3.75 ; nicotinic acid $3 ; \mathrm{B}_{12}$ (1/1000 in mannitol) 2.5 ; calcium-D-pantothenate 2 ; thiamin $\mathrm{HCl} 0.5$; riboflavin 0.5 ; pyridoxine $\mathrm{HCl} 0.5$; folic acid 0.25 ; Rovimix $\mathrm{H}$ (biotin 1\%) 5; menaphthone 0.05; Rovimix E-25 (0.25 mg dl- $\alpha$-tocopherol/ $\mathrm{mg}$ of mix) 15; Rovimix A-500 (500 IU of ester, alltrans, of vitamin $\mathrm{A} / \mathrm{mg}$ ) 0.69 ; Rovimix $\mathrm{A}-500 / \mathrm{D}_{3}-100$ 0.61 ; choline bitartrate 90 ; cellulose carrier as solka floc 875.5. This diet was based on that used by Professor J. Yudkin and his colleagues at Queen Elizabeth College, London.

\section{Preparation of Tissue Extracts}

The retinas were dissected from the living anaesthetized animals (Nembutal $7.2 \mathrm{mg} / 100 \mathrm{~g}$ body weight i.p.) and placed in perchloric acid within 5 seconds. A small portion of liver from the living animal was excised into liquid nitrogen within 1 second, ground, and homogenised in perchloric acid. Blood was led from the beating heart directly into perchloric acid. All the extracts were adjusted to $\mathrm{pH} 6.0$ with potassium carbonate.

\section{Analytical Methods}

Glucose, glucose-6-phosphate and pyruvate were determined fluorimetrically in the retinal extracts with an EEL fluorimeter, model 244, coupled with a Bryans recorder, model 27000. All determinations were carried out at $30^{\circ} \mathrm{C}$ with the instrument standardised to $3 \times 10^{-8} \mathrm{M}$ quinine sulphate solution using an OX 1 filter and an excitation wavelength of $460 \mathrm{~nm}$. Glucose-6-phosphate was also determined fluorimetrically in the blood and liver. The methods are based on those used by Lowry et al. [9].

All other determinations were carried out spectrophotometrically using an SP 700 recording spectrophotometer with a light path of $1 \mathrm{~cm}$. Lactate and pyruvate were determined by the method of P. TfeltHansen and O. Siggaard-Andersen [10]. This method for lactate was found to give very stable blank values essential for the accurate analysis of the small quantities present in retinal extracts. The glucose contents of the blood and liver were determined by the coupled enzymic reaction of HK, G6PDH and NADP [11].

\section{Results}

\section{Changes in Liver and Body Weights}

Normal rats maintained on diets, in which the carbohydrate consisted only of starch or sucrose, gained weight at equal rates (Table 1$)$. The rats fed on sucrose diets, however, had larger livers $(p<0.005)$ than those maintained on the starch diet and the amount of liver $/ 100 \mathrm{~g}$ body weight was also greater $(p<0.001)$. After the animals were rendered moderately diabetic both dietary groups failed $(p<0.001)$ to gain weight. The whole liver of the sucrose-fed diabetic rats was heavier $(p<0.001)$ than the liver from the sucrose-fed normal animals, whereas the mean weight of the livers from the starch-fed diabetic group was less than that of the normal starch-fed animals $(p<0.01)$. When, however, one considers the weight of liver $/ 100 \mathrm{~g}$ body weight both the starchand sucrose-fed diabetic animals had bigger livers than those in correspondingly fed normal groups $(p<0.005$ and $p<0.001$ respectively). 


\section{Changes in Tissue Glucose}

The maintenance of normal rats on diets where the sole source of carbohydrate was either starch or sucrose resulted in comparable blood, retina and liver glucose levels (Table 2). When the animals were made moderately diabetic, however, the resulting blood glucose levels were higher in the starch-fed animals than

\section{Changes in Tissue Glucose-6-Phosphate}

In both the retina and the blood neither the diet nor the diabetic state had any marked effect on the G6P content (Table 3). In the liver, however, the G6P level was higher in the starch normal rats when compared with sucrose normal $(p<0.001)$ or starch diabetic rats $(p<0.025)$.

Table 1. Body and liver weights of normal and streptozotocin-diabetic rats maitained for 20 days on starch-or sucrose-rich diets

\begin{tabular}{lllll}
\hline & Weight $(\mathrm{g})$ & \multicolumn{2}{l}{ Mean of 8 determinations \pm S.E.M. } \\
\hline $\begin{array}{l}\text { Growth } \\
\text { parameter }\end{array}$ & $\begin{array}{l}\text { Starch } \\
\text { normal }\end{array}$ & $\begin{array}{l}\text { Sucrose } \\
\text { normal }\end{array}$ & $\begin{array}{l}\text { Starch } \\
\text { diabetic }\end{array}$ & $\begin{array}{l}\text { Sucrose } \\
\text { diabetic }\end{array}$ \\
\hline Body wt gain & $+85 \pm 9.8$ & $+83 \pm 6.0$ & $-3 \pm 9.9$ & $+16 \pm 10$ \\
Liver wt: total & $9.4 \pm 0.37$ & $11.0 \pm 0.3$ & $7.9 \pm 0.5$ & $11.3 \pm 0.8$ \\
Liver wt/100 g rat & $3.6 \pm 0.08$ & $4.3 \pm 0.08$ & $4.0 \pm 0.11$ & $5.0 \pm 0.16$ \\
\hline
\end{tabular}

Table 2. Glucose content of retina, blood and liver from normal and streptozotocindiabetic rats maintained on starch-or sucrose-rich diet for 20 days

\begin{tabular}{lccll}
\hline & $\begin{array}{l}\text { Glucose } \\
\mathrm{mg} / 100 \mathrm{~g}\end{array}$ & Mean of 8 determinations \pm S.E.M. \\
\hline Tissue & $\begin{array}{l}\text { Starch } \\
\text { normal }\end{array}$ & $\begin{array}{l}\text { Sucrose } \\
\text { normal }\end{array}$ & $\begin{array}{l}\text { Starch } \\
\text { diabetic }\end{array}$ & $\begin{array}{l}\text { Sucrose } \\
\text { diabetic }\end{array}$ \\
\hline Retina & $52 \pm 4.7$ & $45 \pm 3.8$ & $231 \pm 25.5$ & $196 \pm 18.3$ \\
Blood & $112 \pm 7.2$ & $114 \pm 5.2$ & $520 \pm 29$ & $384 \pm 35$ \\
Liver & $122 \pm 7.5$ & $117 \pm 8.3$ & $461 \pm 34.7$ & $365 \pm 30.2$ \\
\hline
\end{tabular}

Table 3. Glucose-6-phosphate (G6P) content of retina, blood and liver from normal and streptozotocin-diabetic rats maintained on starch-or sucrose-rich diet for 20 days

\begin{tabular}{lllll}
\hline & G6P & \multicolumn{2}{l}{ Mean of 8 determinations \pm S.E.M. } \\
& $\mu$ mol/100 $\mathrm{g}$ & & & \\
\hline Tissue & Starch & Sucrose & Starch & Sucrose \\
& normal & normal & diabetic & diabetic \\
\hline Retina & $15.4 \pm 1.6$ & $12.2 \pm 2.0$ & $19.8 \pm 2.3$ & $13.8 \pm 3.6$ \\
Blood & $2.6 \pm 0.3$ & $2.7 \pm 0.3$ & $3.1 \pm 0.6$ & $2.4 \pm 0.2$ \\
Liver & $22.3 \pm 1.6$ & $13.4 \pm 1.5$ & $16.4 \pm 2.2$ & $12.9 \pm 3.2$ \\
\hline
\end{tabular}

in those maintained on sucrose $(p<0.01)$. Sucrose feeding had a similar effect on the glucose content of the diabetic rat livers $(p<0.05)$; however, the increase in the retinal glucose content of the starch-fed diabetic animals was not significant. The retinas of the diabetic animals were found to contain more glucose $(p<0.001)$ than those of the normals. In both the starch- and sucrose-fed animals there was a positive correlation between the glucose level in the blood and the glucose content of the retina $(r=0.86, p<0.001$ and $r=0.92, p<0.001$ respectively). There was a correlation between the blood and liver glucose $(r=0.96, p<0.001)$ in the starch-fed animals.

\section{Changes in Tissue Lactate}

The level of lactic acid in the normal rat retina is considerably higher than that in either the blood or the liver and the feeding of sucrose to normal animals results in an increase $(p<0.001)$ in the lactic acid content of the retina (Table 4$)$. This was also increased $(p<0.001)$ in the diabetics on the starch diet. It will be noticed that in the diabetics sucrose feeding did not result in higher retinal lactic acid levels than starch feeding. There was a positive correlation between the lactic acid content of the blood and the retina in the starch-fed animals $(r=0.68, p<0.01)$, 
but the level of lactic acid in the retina was not related to that in the blood when the rats were maintained on a sucrose diet. Although the lactic acid content of the retina was increased by sucrose feeding the level of this substrate was not significantly altered in the blood or the liver of normal animals. Also, in the diabetic state, sucrose feeding did not cause any significant changes in the lactic acid content of either the blood or the liver, whereas starch feeding resulted in an

\section{Changes in Tissue Pyruvate}

In the retina neither the type of carbohydrate nor the diabetic condition caused any significant change in the pyruvate content of this tissue (Table 5). There was an increase in the pyruvic acid content of the blood of the starch-fed rats when rendered diabetic $(p<0.01)$; but in this diabetic state sucrose feeding resulted in a lower content of pyruvic acid in the

Table 4. Lactic acid content of retina, blood and liver from normal and streptozotocindiabetic rats maintained for 20 days on either starch-or sucrose-rich diet

\begin{tabular}{lllll}
\hline & \multicolumn{2}{l}{ Lactic acid $\mu$ moles $/ 100 \mathrm{~g}$} & $\begin{array}{l}\text { Mean of } 8 \text { determinations } \\
\pm \text { S.E.M. }\end{array}$ \\
\hline Tissue & $\begin{array}{l}\text { Starch } \\
\text { normal }\end{array}$ & $\begin{array}{l}\text { Sucrose } \\
\text { normal }\end{array}$ & $\begin{array}{l}\text { Starch } \\
\text { diabetic }\end{array}$ & $\begin{array}{l}\text { Sucrose } \\
\text { diabetic }\end{array}$ \\
\hline Retina & $720 \pm 43$ & $951 \pm 25$ & $1012 \pm 51$ & $999 \pm 100$ \\
Blood & $198 \pm 20$ & $235 \pm 10$ & $468 \pm 61$ & $242 \pm 24$ \\
Liver & $181 \pm 35$ & $229 \pm 28$ & $361 \pm 68$ & $221 \pm 17$ \\
\hline
\end{tabular}

Table 5. Pyruvate content of retina, blood and liver from normal and streptozotocindiabetic rats maintained for 20 days on starch-or sucrose-rich diet

\begin{tabular}{|c|c|c|c|c|}
\hline \multirow[b]{2}{*}{ Tissue } & \multicolumn{2}{|c|}{ Pyruvate $\mu$ moles $/ 100 \mathrm{~g}$} & \multicolumn{2}{|c|}{$\begin{array}{l}\text { Mean of } 8 \text { determinations } \\
\pm \text { S.E.M. }\end{array}$} \\
\hline & $\begin{array}{l}\text { Starch } \\
\text { normal }\end{array}$ & $\begin{array}{l}\text { Sucrose } \\
\text { normal }\end{array}$ & $\begin{array}{l}\text { Starch } \\
\text { diabetic }\end{array}$ & $\begin{array}{l}\text { Sucrose } \\
\text { diabetic }\end{array}$ \\
\hline Retina & $35.6 \pm 4.2$ & $30.4 \pm 3.4$ & $32.9 \pm 2.8$ & $31.8 \pm 2.6$ \\
\hline Blood & $13.8 \pm 1.3$ & $15.7 \pm 1.1$ & $19.6 \pm 1.5$ & $14.5 \pm 0.6$ \\
\hline Liver & $7.3 \pm 1.7$ & $13.1 \pm 2.2$ & $5.2 \pm 0.4$ & $8.9 \pm 2.4$ \\
\hline
\end{tabular}

Table 6. Lactate/pyruvate ratios of retina, blood and liver from normal and streptozotocin-diabetic rats maintained for 20 days on starch-or sucrose-rich diet

\begin{tabular}{lllll}
\hline & \multicolumn{2}{l}{ Lactate/pyruvate ratio } & \multicolumn{2}{l}{$\begin{array}{l}\text { Mean of 8 determinations } \\
\pm \text { S.E.M. }\end{array}$} \\
\hline Tissue & Starch & Sucrose & $\begin{array}{l}\text { Starch } \\
\text { diabetic }\end{array}$ & $\begin{array}{l}\text { Sucrose } \\
\text { diabetic }\end{array}$ \\
\hline normal & normal & $35 \pm 4.9$ & $32 \pm 1.7$ & $34 \pm 6.5$ \\
Blood & $21 \pm 2.9$ & $34 \pm 2.2$ & $17 \pm 1.4$ \\
Liver & $14 \pm 0.8$ & $15 \pm 0.9$ & $24 \pm 0.7$ & $33 \pm 5.8$ \\
\hline
\end{tabular}

increase in both the lactic acid content of the blood $(p<0.001)$ and liver $(p<0.025)$. The lactic acid content of the liver was correlated with that in the blood on both starch $(r=0.88, p<0.001)$ and sucrose $(r=0.62, p<0.01)$ diets. In the starch-fed animals there was a positive correlation between the glucose and lactic acid contents of retina $(r=0.66, p<0.01)$. On the other hand there was no significant relationship between the glucose and the lactic acid content of all three tissues when the animals were maintained on the sucrose diet. blood as compared with starch feeding $(p<0.005)$. The feeding of sucrose caused an increase in the liver both of normal $(p<0.05)$ and diabetic rats $(p<$ 0.025 ). On the other hand the feeding of starch to the diabetic animals reduced the pyruvate content of the liver and the feeding of sucrose caused a significant decrease $(p<0.025)$.

\section{Changes in Tissue Lactate/Pyruvate Ratio}

Diabetes caused the lactate/pyruvate $(\mathrm{L} / \mathrm{P})$ ratio to be increased in all three tissues of the starch-fed 
animals $(p<0.005)$ (Table 6). In the sucrose-fed animals, however, there were no significant changes in either the retina or the blood, but the $\mathrm{L} / \mathrm{P}$ ratio was increased in the liver $(p<0.05)$. The effects of sucrose feeding on the $L / P$ ratio in normal animals is mainly a reflection of the lactic acid content of these tissues. In the starch-fed, but not in the sucrosefed animals, there was a positive correlation between glucose and the $\mathrm{L} / \mathrm{P}$ ratio in the blood $(r=0.78$, $p<0.001)$ and in the liver $(r=0.74, p<0.001)$.

\section{Discussion}

Many workers have noted liver hypertrophy [12, $13,14]$ in the sucrose-fed, non-diabetic rat; in these investigations significant increases were observed in the total liver size and in the weight of liver $/ 100 \mathrm{~g}$ body weight of the normal sucrose-fed rat, compared with the starch-fed animal. This increase in liver size is due mainly to the deposition of glycogen [15] and a concomitant increase in the water content of the liver. There is also an increase in the triglyceride content of the liver and Maruhama and MacDonald [16] have recently demonstrated, by the use of fructose-U${ }^{14} \mathrm{C}$, the rapid formation and incorporation of $\alpha$-glycerophosphate into the triglycerides of the liver. Bruckdorfer et al. [17] have also shown increased lipogenesis in the livers of sucrose-fed normal rats and an elevation in fatty acid synthetase activity. An even larger increase in liver size and weight of liver/ $100 \mathrm{~g}$ body weight was observed in the present studies in the case of the sucrose-fed diabetic animals, the weight of liver $/ 100 \mathrm{~g}$ being $5.0 \mathrm{~g}$ compared with $3.6 \mathrm{~g}$ for the starch-fed normal animals. This increase in liver size in the sucrose-fed diabetic animals was therefore probably due to increases in the glycogen and triglyceride content; both synthetic processes could account for the lower lactic acid content observed in the livers of the diabetic animal after sucrose feeding.

The results of the present investigation show that the feeding of sucrose to normal rats for 20 days caused a significant increase in the lactic acid content of the retina. This was not due to any increase in either the glucose or the pyruvate content of the retina since the levels of these substances in this tissue were unchanged by sucrose feeding. The $\mathrm{L} / \mathrm{P}$ ratio was markedly increased in the retina and this is indicative of a decrease in the NAD/NADH ${ }_{2}$ ratio. Such a decrease has previously been reported [18] to occur in the retinas of the alloxan-diabetic rat, the ratio falling from 5.4 in the normal to 4.2 in the diabetic state.
Comparable alterations in the lactic acid content and the $\mathbf{L} / \mathbf{P}$ ratio did not occur in the blood of the sucrose-fed normal rats and the high lactic acid content of the retina in the sucrose-fed animals could not, therefore, have been derived directly from the blood glucose or lactate, but must have been due to an alteration in the metabolism of the retina itself. Sucrose is rapidly cleaved by the brush border sucrase of the intestinal mucosa into glucose and fructose [19] and, although the levels of fructose in the blood of normal animals are usually low, since fructose is rapidly metabolised by the liver the levels of this hexose in the blood are not negligible during sucrose feeding and can be up to $25 \%$ of the total reducing sugar content [12]. It would seem likely, therefore, that the increase in lactic acid observed in the retina was derived either directly or indirectly from the fructose moiety of the ingested sucrose. The rapid phosphorylation of fructose by fructokinase to yield fructose-1-phosphate has been reported [20] to result in a decrease in the level of ATP and this may account for the significantly lower content of glucose-6-phosphate found in the liver of the sucrose-fed normal animals in the present study. There was also an observed decrease of $20 \%$ in the glucose-6-phosphate content of the retina from the sucrose-fed rats.

In designing these experiments, it was thought that the superimposition of streptozotocin-diabetes on the administration of sucrose to the rats would result in even higher levels of lactic acid in the tissues, since both the feeding of sucrose to healthy subjects [8] and the presence of diabetes [21] have been reported to induce an elevation in the lactic acid content of the blood. In these investigations, however, the two regimens were found not to be additive in their effects on the lactic acid levels.

When the animals were maintained on the starchrich diet the contents of lactic acid in all three tissues were significantly increased after the animals had been rendered diabetic and there were also significant increases in the $\mathrm{L} / \mathrm{P}$ ratios in all tissues. There was a positive correlation between the glucose and the lactic acid contents of the tissues indicating that the increase in lactate had been derived from the elevated glucose concentrations. In the case of the sucrose-fed animals, there was unexpectedly no alteration in the lactic acid content of either the retina, blood or liver caused by the diabetic state. There was, however, a significant increase in the glucose content of all three tissues of the sucrose-fed animals, but there was no correlation between the tissue glucose and lactate levels.

When one compares the starch-fed to the sucrosefed diabetic animals it will be seen that starch feeding results in poorer diabetic control with respect to both 
the glucose and lactic acid content of the blood and liver, both these constituents being significantly higher in the starch-fed animals. In the retina, however, no significant changes were observed between either diet in the diabetic state. It would appear, therefore, as though there were factors in the retina limiting the formation of lactic acid at approximately $1 \mathrm{mmol} /$ $100 \mathrm{~g}$. This value is considerably higher than that found for either the blood or the liver and is in keeping with the well established capacity of the retina for anaerobic glycolysis.

Acknowledgements. This research was generously supported by the Clothworkers' Company and the British Foundation for Research into the Prevention of Blindness. The authors are grateful to Miss J. R. Hodsdon for her cooperation and assistance, to Glaxo Laboratories Ltd. and Roche Products for a generous gift of vitamins and to Upjohn Ltd. who donated the streptozotocin.

\section{References}

1. Cohen, A. M., Michaelson, I. C., Yanko, L.: Retinopathy in rats with disturbed carbohydrate metabolism following a high sucrose diet. Amer. J. Ophthal. 73, 863-869 (1972)

2. Cohen, A. M., Freund, H., Auerbach, E.: Electroretinogram in sucrose- and starch-fed rats. Metabolism 19, 1064-1067 (1970)

3. Cohen, A. M., Shoshan, S.: Effect of glucose, fructose and starch on aorta collagen in the rat. J. Atheroscler. Res. 8, 371-375 (1968)

4. Heath, H., Paterson, R. A., Hart, J. C. D.: Changes in the hydroxyproline, hexosamine and sialic acid of the diabetic human and $\beta, \beta^{\prime}$-iminodipropionitrile-treated rat retinal vascular systems. Diabetologia 3, 515-518 (1967)

5. Leuenberger, P., Cameron, D., Stauffacher, W., Renold, A. E., Babel, J.: Ocular lesions in rats rendered chronically diabetic with streptozotocin. Ophthal. Res. 2, 189-204 (1971)

6. Babel, J., Leuenberger, P.: A long term study on the ocular lesions in streptozotocin diabetic rats. Albrecht v. Graefes Arch. Ophthal. 189, 191-209 (1974)

7. Keen, H., Chlouverakis, C.: Metabolic factors in diabetic retinopathy. In: Graymore, C. N.: Biochemistry of the retina, p. 134. London and New York: Academic Press 1965

8. Dodds, C., Miller, A. L., Rose, C. F. M.: Blood pyruvate and lactate response of normal subjects to dextrose, sucrose and liquid glucose. Lancet 1960 II, 178--180

9. Lowry, O. H., Passonneau, S. V., Hasselberger, F. X.,
Schulz, D.: Effect of ischemia on known substrates and cofactors of the glycolytic pathway in brain. J. biol. Chem. 239, 18-30 (1964)

10. Tfelt-Hansen, P., Siggaard-Andersen, O.: Lactate and pyruvate determination in $50 \mu 1$ whole blood. Scand. J. clin. Lab. Invest. 27, 15-19 (1971)

11. Stein, M. W.: D-glucose, determination with hexokinase and glucose-6-phosphate dehydrogenase. In: Bergmeyer, H. U.: Methods of enzymatic analysis, p. 117. New York and London: Academic Press 1963

12. Bruckdorfer, K. R., Kang, S. S., Khan, I. H., Bourne, A. $R$., Yudkin, J.: Diurna1 changes in the concentrations of plasma lipids, sugars, insulin and corticosterone in rats fed diets containing various carbohydrates. Horm. Metab. Res. 6, 99-106 (1974)

13. Bender, A. E., Thadani, P. V.: Some metabolic effects of sucrose. Nutr. Metabol. 12, 22-39 (1970)

14. Bender, A. E., Damji, K. B., Khan, M. A., Khan, I. H., McGregor, L., Yudkin, J.: Sucrose induction of hepatic hyperplasia in the rat. Nature 238, $461-462$ (1972)

15. Kang, S. S.: Effects of dietary carbohydrates on lipid metabolism in the rat. Ph. D. Thesis: University of London 1973

16. Maruhama, Y., MacDonald, I.: Incorporation of orally administered glucose-U-14C and fructose-U-14C into the triglyceride of liver plasma and adipose tissue of rats. Metabolism 22, 1205-1215 (1973)

17. Bruckdorfer, K. R., Khan, I. H., Yudkin, J.: Fatty acid synthetase activity in the liver and adipose tissue of the rats fed with various carbohydrates. Biochem. J. 129, 439446 (1972)

18. Heath, H., Rutter, A. C., Beck, Th. C.: Reduced and oxidised pyridine nucleotides in the retinae from alloxandiabetic rats. Vision Res. 2, 333-342 (1962)

19. Gray, G. M., Ingelfinger, F. J.: Intestinal absorption of sucrose in man: interrelation of hydrolysis and monosaccharide product absorption. J. clin. Invest. 45, 388- 398 (1966)

20. Woods, H. F., Alberti, K. G. M. M.: Dangers of intravenous fructose. Lancet 1972 II, 1354-1357

21. Hohorst, J. H., Kreutz, F. M., Reim, M., Hubener, H. J.: The oxidation/reduction state of the extramitochondrial DPN/DPNH system in rat liver and the hormonal control of substrate levels in vivo. Biochem. biophys. Res. Commun. 4, 163-168 (1961)

\author{
Dr. H. Heath \\ Department of Biochemical Pathology \\ University College Hospital, Medical School \\ University Street \\ London WC1E 6JJ \\ England
}

